\title{
LA ANTÍFRASIS EN CÁNDIDO DE VOLTAIRE
}

\author{
Beatriz Rodríguez Oconitrillo
}

\begin{abstract}
RESUMEN
Este artículo trata sobre la antífrasis en Cándido. Se analizarán las herramientas linguiísticas que Voltaire utiliza para ironizar con el fin de demostrar la influencia directa de la ironía en este texto literario.
\end{abstract}

\begin{abstract}
This article deals with the study of antiphrase in Candide. Linguistic tools used by Voltaire to ironize will be analized in order to demonstrate the direct influence of irony in this literary text.
\end{abstract}

Les livres les plus utiles sont ceux dont les lecteurs font eux-mêmes la moitié.

Voltaire

Voltaire, uno de los más ilustres escritores franceses del siglo XVIII, nos transporta por medio de Cándido a un mundo fantástico, absurdo, cómico, cruel. Desde la primera publicación de este cuento las críticas no se hicieron esperar. No olvidemos que este fue escrito en el transcurso de un siglo particularmente agitado en materia política, social y religiosa. El lector de aquella época concebía entonces este texto como una verdadera crítica social. Es por esto que la ironía voltairiana tiene grandes posibilidades de haber chocado aún más con el lector del siglo XVIII que con el del siglo XX. Al no poder presentar aquí un estudio muy extenso sobre la ironía en Cándido, nos limitaremos entonces a presentar el texto literario, a definir los conceptos utilizados (la retórica, la ironía, la antífrasis) y a exponer brevemente las ideas de Leibniz y de Voltaire. Seguidamente, daremos una sinopsis del cuento y luego presentaremos las estructuras irónicas que estudiaremos, los objetivos y el método de análisis. Posteriormente, pasaremos al análisis de diez pasajes irónicos que contienen la antífrasis. Y para terminar, expondremos nuestras conclusiones propias a este estudio.

\section{El texto literario}

El texto literario se sitúa entre los mensajes lingüísticos que pertenecen a lo "escriturario, aquel en donde el mensaje es producido por una cadena de grafemas y percibido visualmente" 
(Peytard 1982: 116). Esos grafemas son signos (es decir que existe la unión de un significante y un significado) portadores de una significación y producidos por un escriptor quien ofrece su "producto literario" (Peytard 1982: 116) a un público potencial. En nuestro caso, el escriptor — autor de la obra en estudio— es Voltaire y Cándido, su producto; por su parte el lector juega el papel de público encargado de descubrir la ironía.

Para transmitir su mensaje, el escriptor puede servirse de un determinado número de personajes o hablar por medio del narrador: un personaje $x$ (el emisor, codificador del mensaje, es decir aquel que lo produce) puede dirigirse a un personaje $y$ (el destinatario, descodificador del mensaje, es decir aquel que lo interpreta). Hay que precisar que en Cándido, no es nunca el personaje quien descifra el mensaje irónico, sino el lector. Y cuando surge el narrador ausente, Voltaire, este se dirige a un lector potencial. En este mensaje hay también que tomar en cuenta el contexto (aquello de lo que se habla, el referente).

Cada uno de esos factores (emisor, destinatario, contexto) tendrá una función lingüística diferente (Jakobson 1963: 214). Estudiaremos aquí solamente dos funciones que nos convienen para el estudio de la ironía: la función referencial y la función conativa.

a. La función referencial: su rol es remitir al referente. Jakobson afirma que "para producir un efecto, el mensaje requiere primeramente de un contexto al que él refiere" (1963: 213). En el caso específico de la ironía, ese contexto está representado por el objeto o la persona a quien la ironía se dirige, es decir por lo que el escriptor denuncia o ridiculiza. Aquí surge la finalidad de la ironía, su "valor ilocutorio" (KerbratOrecchioni 1980: 119) que consiste precisamente en denunciar o ridiculizar algo o a alguien. Podemos entonces afirmar que la ironía contiene un "componente ilocutorio" (Kerbrat-Orecchioni,citada por Muecke 1978: 479).

En los pasajes que estudiaremos, el escriptor se burla principalmente de la filosofía de Leibniz, de la nobleza y de las riquezas materiales. Denuncia además, los horrores de la guerra y las atrocidades de la Inquisición, aspectos que serán explicados en el análisis.

b. La función conativa: el mensaje se centra aquí en el destinatario. Efectivamente, el emisor busca provocar en el lector una reacción determinada. Aparece entonces la función que tiene como eje central el destinatario (el lector en ese momento) cuando este toma conciencia de los aspectos a los que apunta la ironía.

Para el desciframiento de la ironía, el lector está en la obligación de poseer competencias lingüísticas (dominar la lengua utilizada) así como competencias culturales e ideológicas (conocer, por ejemplo, los principios fundamentales de los sistemas filosóficos de Leibniz y de Voltaire, o las ideas políticas, sociales y religiosas del escriptor). El lector debe estar consciente de la existencia de la ironía en un texto; de otro modo, esta no existe.

Además del componente ilocutorio, la ironía recurre a un "componente retórico" (Kerbrat-Orecchioni 1980: 119), es decir que esta se expresa a través de diferentes procedimientos como la antífrasis. 


\section{La retórica, la ironía, la antífrasis}

\subsection{La retórica}

Este concepto es necesario en nuestro estudio, ya que la ironía es una figura retórica. La retórica atraviesa los siglos y los regímenes. Nace en Sicilia en el año 485 antes de Cristo y sobrevive hasta finales del siglo XIX. En los años sesenta retoma fuerza cuando aparecen varios estudios de formalistas rusos — como Jakobson y Propp— quienes parten de la idea de que todo discurso contiene reglas.

El Dictionnaire des littératures señala que desde los tiempos de Aristóteles, el arte de convencer es objeto de estudio: con la ayuda de razonamientos deductivos rigurosos llamados silogismos, Aristóteles trataba de convencer a su auditorio (1987: 2065).

Hay que recordar que en el estudio de la retórica, existen cinco componentes del discurso: la inventio (la búsqueda de ideas, de contenido), la dispositio (organización de las partes), la elocutio (escogencia y disposición de las palabras), la memoria (el orador debe decir su discurso de memoria), y la acción (producción del discurso, incluyendo los gestos; actualmente la semiótica gestual se ocupa de la acción). Hoy día, el ingrediente esencial de la retórica es la "elocutio".

Generalmente las definiciones de retórica se apoyan en la relación que un sujeto instaura con su auditorio; la utilización de la palabra tiene como objetivo persuadir el auditorio, provocar en él una actitud determinada. D. Maingueneau manifiesta que es el "estudio de los medios discursivos que un sujeto determinado utiliza para persuadir un auditorio determinado" (1976: 144). El autor parte de dos elementos importantes: por una parte, la acción del sujeto; por otra parte, los procedimientos que él utiliza para alcanzar su objetivo: convencer.

Citemos ahora a H. Lemaître quien propone una definición sintética y apropiada:

(...) la noción de retórica se aplica al conjunto de los procedimientos de composición y estilo que confieren al lenguaje y a la palabra su poder específico en un lector o en un auditorio" (1985: 658-9).

En el caso específico de Cándido, el escriptor actúa como el sujeto que desea convencer al lector. Voltaire emplea, para este fin, una serie de procedimientos que van a caracterizar su estilo.

\subsection{La ironía}

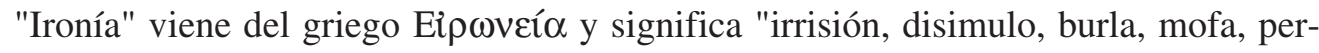
mutación" (Fontanier 1977: 263). Cuando Sócrates fingía la ignorancia e interrogaba a sus interlocutores poniendo en evidencia la ignorancia de estos, estaba ya haciendo ironía, con el método llamado mayéutica.

Tradicionalmente, la ironía es considerada como la disposición y la actitud general de un individuo (Allemann 1978: 386).

Sin embargo, Allemann estima que la ironía es asimismo una "actitud estilística" del autor. (1978: 386). 
Hay que mencionar el hecho de que la retórica clásica reconocía la ironía solamente bajo la forma de la antífrasis. Contrariamente, la concepción actual es más extensa, como lo prueban las definiciones que daremos más adelante.

Sería interesante presentar el punto de vista de un rétorico del siglo XVIII y la opinión del retórico moderno, para poder así comparar sus opiniones.

Para Fontanier, la ironía consistía en decir por medio de una burla — divertida o seria- lo contrario de lo que se pensaba o de lo que se quería hacer pensar (1977: 145-6). La definición extraída del Trésor de la langue française y descrita como "figura de retórica por medio de la cual se dice lo contrario de lo que se quiere hacer comprender" (1983: 548) llama nuestra atención por el hecho de que se trata de lo que se "dice" y no de lo que se piensa. Estas dos definiciones son limitadas y se refieren solamente al procedimiento irónico, objeto de nuestro estudio: la antífrasis.

Basaremos por lo tanto nuestro análisis en estas definiciones, sabiendo, sin embargo, que la ironía puede ser -y estudios de esto lo prueban-, "burlarse, más que hablar por medio de antífrasis" (Kerbrat-Orecchioni 1980: 120).

\subsection{La antífrasis}

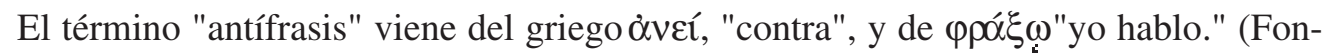
tanier 1977: 265). Es una figura por medio de la cual, por temor, escrúpulo o ironía, se emplea una palabra, un nombre propio, una frase, una locución, con la intención de expresar lo contrario de lo que se ha dicho" (Trésor de la langue française 1983: 164).

En Cándido, el escriptor utiliza, en un diálogo o en una narración, un significante (generalmente un adjetivo o a veces un sustantivo) queriendo hacer entender lo contrario de lo que este significa. Este significante ( $\mathrm{Sa}$ ) está asociado a dos significados diferentes que representaremos de ahora en adelante como: Sé 1, Sé 2 ("signifié" en francés). Observemos el siguiente triángulo propuesto por Kerbrat-Orecchioni (1979: 779):

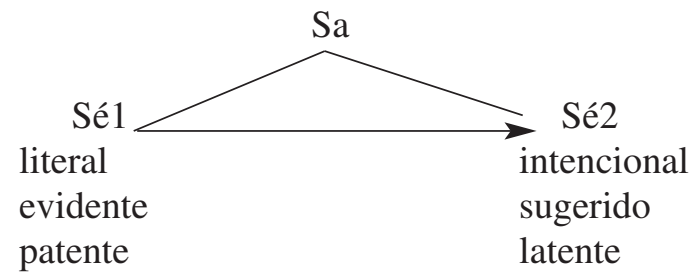

Los dos significados tienen una relación de antonimia, es decir que son significados contrarios. Kerbrat-Orecchioni caracteriza al Sé1 como literal, evidente, patente, y al Sé2 como intencional, sugerido, latente. Sin embargo, no existe antonimia perfecta entre estos significados, el contrario de "gran" puede ser por ejemplo "mediocre"; ahora bien, en Cándido, la mediocridad no será exactamente lo que el personaje o el narrador pondrán en tela de juicio.

Para el análisis de la antífrasis, hablaremos de un sentido literal para el Sé1 y de un sentido intencional para el Sé2. Este sentido literal estará basado en las definiciones del diccionario Le Petit Robert, edición de 1988. El segundo sentido será nuestra interpretación de lo que el escriptor haya querido hacer entender en el lugar del Sé1. 
El Sé1 debe ser descifrado en primera instancia, y es solamente en un segundo paso que el Sé2, que contiene un "implícito discursivo", será deducido del Sé1 ( Kerbrat-Orecchioni 1979: 780).

De esta manera, en los significantes "gran filósofo", el adjetivo "gran" tendrá dos significados contrarios, uno de ellos será literal y el otro intencional:

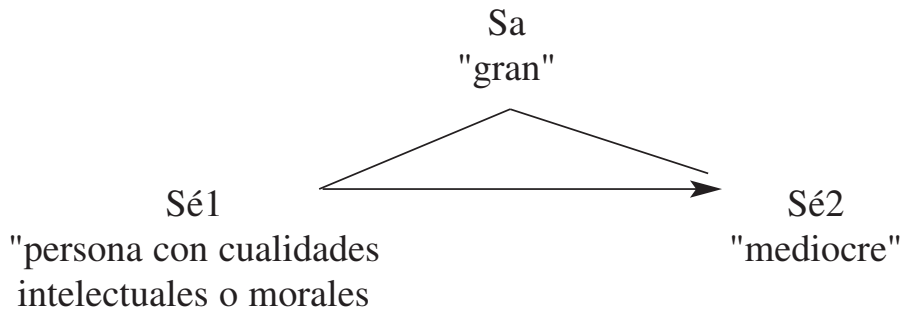

\section{Ideas filosóficas de Leibniz y de Voltaire}

Leibniz, filósofo alemán del siglo XVII, le da un lugar privilegiado a la metafísica y la sitúa a la cabeza de toda física pues a su parecer, lo que debe ser examinado en primer lugar es "la razón de ser de las cosas". Voltaire criticará este principio, pues cree que la razón recaerá de forma excesiva sobre fenómenos ya de todos modos incomprensibles para el hombre. Atacará también el principio de "armonía preestablecida", de acuerdo a la cual las cosas están entrelazadas necesariamente unas con otras. Para el autor de Cándido, esto es negar la libertad del hombre.

Para Leibniz, Dios ha creado el mundo de la mejor manera posible. Sin embargo, desde su creación, el mundo era imperfecto y contenía ya el mal. Es entonces que aparece una filosofía optimista expuesta por Leibniz en sus Essais de Théodicée (1710), divulgada por su discípulo Wolff (1679-1754).

Voltaire refuta este optimismo por medio del cual es posible justificar el mal, abusando del argumento "todo es de lo mejor en el mejor de los mundos posibles" ("tout va pour le mieux dans le meilleur des mondes possibles"). El lado mecánico y absurdo de esta filosofía va a ser ridiculizado, y esta filosofía va a ser llevada a los extremos, aplicándola hasta en los más pequeños hechos de la vida cotidiana.

Siendo filósofo del Siglo de las Luces, Voltaire no cesará de hacer burla de la nobleza y la religión. Partidario irreductible de la tolerancia religiosa, atacará los hechos impregnados de fanatismo, como el caso de la Inquisición.

Es a través de un cuento que Voltaire expondrá sus ideas.

\section{Cándido, cuento filosófico}

Redactado en 1758 y publicado al año siguiente, este cuento satírico fue escrito contra Leibniz y sus discípulos y trata el problema de la existencia del mal en el mundo. 
Los dos personajes principales son Cándido y su maestro Pangloss. Cándido es una presa ideal para la educación metafísica de Pangloss. Constantemente, Voltaire mostrará que esta ciencia es perjudicial para un verdadero conocimiento del mundo, esta obstaculizará las enseñanzas que nos da la experiencia y retrasará la formación autónoma. Por su parte, Pangloss, portavoz de Leibniz, razona erradamente: afirma sin demostrar o saca conclusiones absurdas y arbitrarias.

\section{Las estructuras objeto de estudio, objetivos y método de análisis}

Veremos a lo largo de nuestro recorrido que las construcciones gramaticales simples son una de las características de este cuento; sin embargo, se esconden bajo éstas ideas profundas. Nos centraremos en el estudio de la ironía verbal en diez pasajes que contienen significantes irónicos con las siguientes estructuras: Sustantivo + Adjetivo y Adjetivo + Sustantivo. Partiremos de un mismo método de análisis y observaremos las herramientas lingüísticas que el escriptor utiliza para ironizar. Dos razones sustentan la escogencia de estas estructuras: la gran frecuencia de estos significantes a través de todo el cuento nos hace suponer la posibilidad de una intención particular del escriptor; queremos también mostrar que significantes —en apariencia simples_ - pueden dar lugar a operaciones complejas de desciframiento.

Los objetivos que nos hemos propuesto son los siguientes:

1. Estudiar la situación de enunciación de cada extracto: observar las personas u objetos implicados en la ironía (el emisor, el destinatario, el blanco: objeto u persona a quien va dirigida la ironía). De esta manera, será descubierto el responsable de la enunciación y hacia qué o quién se dirige la burla.

2. Estudiar los índices textuales de la situación de enunciación:

a. los indicios formales de la enunciación: Sophie Moirand afirma que estos representan la presencia del escriptor en el discurso, por ejemplo, el uso de la primera persona "yo", "nosotros"; los indicadores espacio-temporales como "mañana", "aquí", etc. (Moirand 1979: 13).

b. las modalidades de enunciación: la frase puede recibir una de las modalidades siguientes: declarativa, interrogativa, imperativa, exclamativa. (Dubois citado por Maingueneau 1976: 111). Y también las modalidades del enunciado: S. Moirand toma los términos de Maingueneau y habla en primer lugar de las modalidades apreciativas, por ejemplo cuando el escriptor, por medio de adverbios, verbos o adjetivos, expresa su opinión, juzga, valora. En segundo lugar, están las modalidades lógicas: cuando el escriptor sitúa su enunciado como cierto/no cierto, probable/improbable, necesario/innecesario, eventual/no eventual, por medio de expresiones verbales o adverbiales (Maingueneau 1976: 14). Observaremos entonces la marca que el escriptor traza en el enunciado y la relación que él mantiene con éste. 
3. Analizar el mecanismo de la ironía: la forma en que esta funciona, las especificidades de la antífrasis.

4. Mostrar que el desciframiento de la ironía toma en cuenta tres tipos de contexto: el contexto verbal, es decir, las unidades que preceden y que siguen una unidad determinada; el contexto extra-linguístico (lo que sabemos de la realidad, del escriptor), y el contexto de referencia (el objeto o persona de la que se habla).

5. Explicitar la finalidad de la ironía con el fin de descubrir contra qué o contra quién está actuando la ironía.

\section{Análisis de la antífrasis}

\subsection{El adjetivo GRAN + FILÓSOFO}

(En el Pasaje 2 estudiaremos también "buen consejo". Cada pasaje contiene una traducción del extracto en estudio seguido del texto original)

PASAJE 1 En Constantinopla:

1 —Cómo! ¿Es éste nuestro gran filósofo?

2 decía Martin (218).

1 -Quoi! C'est là ce grand philosophe?

2 disait Martin (115).

PASAJE 2 Después de haber matado a un Israelita, Cándido exclama:

$1 \quad$-Si Pangloss no hubiese sido ahor-

2 cado — dijo Cándido- nos daría

3 en esta situación extrema un buen consejo

4 pues era un gran filósofo $(62,64)$.

1 -Si Pangloss n'avait pas été pen-

$2 \mathrm{du}$, dit Candide, il nous donnerait

3 un bon conseil dans cette extrémité,

$4 \quad$ car c'était un grand philosophe $(41,42)$.

En el primer pasaje, el emisor Martin, por medio del adjetivo evaluativo "gran" (Pasaje 1, Línea 1, denominados de ahora en adelante "P" y "L" respectivamente) califica a Pangloss. Recordemos que los adjetivos subjetivos pueden dividirse en afectivos y evaluativos. Los adjetivos afectivos contienen una propiedad del objeto y una reacción emocional. Los adjetivos evaluativos pueden subdividirse en dos: por un lado, los que evalúan cualitativa y 
cuantitativamente el objeto, sin que haya opinión ni compromiso afectivo del emisor; por otro lado, los que contienen una opinión positiva o negativa (Kerbrat-Orecchioni 1980: 84-6). En este contexto, el adjetivo empleado contiene una opinión positiva de Martin hacia Pangloss. Este adjetivo se asocia a dos significados, cuyo Sé1 designa a un individuo que posee cualidades morales e intelectuales. Si nos referimos al contexto de referencia, Pangloss, portavoz de la filosofía optimista rechazada por el escriptor, inferimos que el sentido implícito del Sé2 puede ser mediocre.

En P2, Cándido emplea de nuevo el adjetivo "gran" (L4), que está ligado a los mismos Sé1 y Sé2 definidos en P1. Pero en este caso, el Sé2 se deduce gracias al contexto verbal "Pangloss". El emisor hace uso además de un adjetivo evaluativo "buen" (L3), que traduce su opinión hacia Pangloss. El adjetivo está ligado a dos significados antónimos en donde el Sé1 podría ser "eficaz" y el Sé2 podría significar "ineficaz".

En estos dos pasajes - y en los siguientes - observaremos que el mecanismo de la ironía es el siguiente: basándonos en D.C. Muecke, podemos afirmar que existe un desfase entre "lo que dice (y piensa) L1 (el personaje) y lo que piensa (sin decirlo) Lo (el autor)" (Muecke 1987: 480). Con esto, queremos decir que hay una diferencia evidente entre la enunciación del personaje — es decir cuando la lengua funciona a través de un acto individual de utilización, términos de Benveniste- y lo que el escriptor desea realmente hacer entender.

En P1 y P2, los personajes Martin y Cándido respectivamente valorizan a Pangloss, individuo a quien el escriptor desea en realidad desacreditar.

En P1, la ironía verbal es de situación, ya que Martin, adepto de la filosofía pesimista, alaba a Pangloss, vocero de la filosofía optimista. El signo de exclamación acompañando la interjección "cómo" (L1) marca el asombro y la admiración de Martin hacia Pangloss y sirve para reforzar la ironía.

En P2, el conector argumentativo "pues" (L4) introduce una causa ("pues era un gran filósofo") (L4) que explica lo que acaba de ser enunciado: "él nos daría un buen consejo" (consecuencia). Pero, ¿por qué este empleo es irónico? La ironía reside en el hecho de utilizar una conjunción con el fin de expresar uno de los principios filosóficos de Leibniz: el del vínculo de causa y de consecuencia de un hecho. P. Haffter nos dice al respecto que "el uso consciente de la subordinada causal introducida por "pues" parece ofrecer a Voltaire el medio más apropiado para poner en tela de duda la razón suficiente" (Haffter 1967: 10). Este empleo será retomado por el escriptor en P4. La finalidad de la ironía, siendo común en los pasajes 1 a 6 , será explicada entonces en $\mathrm{P} 6$.

\subsection{El adjetivo GRAN + los sustantivos PANGLOSS, HOMBRE}

(Estudiaremos también en P4 "algo indispensable", "ingrediente necesario", "maravillosos progresos", ya que forman parte del sentido global del pasaje en estudio).

PASAJE 3 Cándido visita al señor Pococurante, noble veneciano:

1 - He aquí, —dijo- un libro que

2 hacía las glorias del gran Pangloss,

3 el mejor filósofo de Alemania (196). 
1 - Voilà, dit-il, un livre qui

2 faisait les délices du grand Pangloss,

3 le meilleur philosophe de l'Allemagne (105).

PASAJE 4 En Holanda, Cándido pregunta a Pangloss si la sífilis contraída por Paquette es obra del diablo. Pangloss explica.

1 -Oh, Pangloss! —exclamó Cándido—. Qué

2 extraña genealogía! ¿No es toda ella

3 cosa del diablo?

4 -No, en absoluto —replicó aquel gran hombre-;

5 era algo indispensable en el

6 mejor de los mundos, un ingrediente necesario:

7 pues si Colón no hubiese pescado en

8 una isla de América esta dolencia que

9 emponzoña la fuente misma de la generación,

10 que con frecuencia llega a impedirla,

11 y que es, evidentemente lo contrario del

12 gran fin de la naturaleza, no tendríamos

13 ni el chocolate ni la cochinilla (...) Mientras

14 tanto, ha hecho maravillosos progresos

15 entre nosotros (...) $(36,38)$

1 -O Pangloss, s'écria Candide, voilà

2 une étrange généalogie! N'est-ce pas

3 le diable qui en fut la souche?

4 -Point du tout, répliqua ce grand homme;

5 c'était une chose indispensable dans le

6 meilleur des mondes, un ingrédient nécessaire:

7 car si Colomb n'avait pas attrapé dans

8 une île de l'Amérique cette maladie qui

9 empoisonne la source de la génération,

10 qui souvent même empêche la génération,

11 et qui est évidemment l'opposé du

12 grand but de la nature, nous n'aurions

13 ni le chocolat ni la cochenille (...) En

14 attendant, elle a fait un merveilleux progrès

15 parmi nous(...) (29)

Observemos primeramente "gran Pangloss" (P3, L2) y "gran hombre" (P4, L4).

En P3, Cándido utiliza el adjetivo "gran"; en P4, es el narrador quien lo emplea a modo de inciso. Los dos califican un referente común: Pangloss. Este adjetivo está ligado a dos significados contrarios: un Sé1 y luego un Sé2 que se deduce de acuerdo al referente Pangloss, 
representante de Leibniz. El Sé1 tiene la misma definición y el Sé2 la misma interpretación que las ya dadas para el pasaje 1 .

En P4, encontramos tres adjetivos empleados por Pangloss, los dos primeros son evaluativos, no hay compromiso afectivo del emisor: "indispensable" (L5) y "necesario" (L6). Estos realzan la necesidad de la existencia de la sífilis. El otro adjetivo es también evaluativo "maravillosos" (L14) pero refleja el juicio positivo de Pangloss hacia la enfermedad.

Esos adjetivos están ligados igualmente a un Sé1 y Sé2; el sentido implícito de éste último se deduce del contexto verbal "esta dolencia" (L8), que se refiere a la sífilis. Al observar que esos adjetivos califican positivamente esta última, creemos que el escriptor ha querido dar a entender lo contrario de lo que expuso su personaje.

El Sé1 de "indispensable" puede definirse como algo de lo que no podemos privarnos, algo esencial; en oposición, el Sé2 puede significar "superfluo". El significante "indispensable" es acompañado de un sinónimo "necesario", que comprende por lo tanto un Sé2 idéntico al propuesto para "indispensable". El Sé1 de "maravillosos" deja entrever algo excepcional en su género, opuesto al Sé2 que podría designar algo "horrible".

Observemos el adverbio "evidentemente" (L11), que marca una modalidad lógica, ya que pone en evidencia la seguridad con que Pangloss pronuncia palabras aberrantes, acentuando esto aún más la ironía.

Algunos aspectos que hacen resaltar la ironía merecen ser comentados: en primer lugar, en P3, los significantes "gran Pangloss" están reforzados por el superlativo "el mejor". Esto significa que Pangloss no es solamente un gran individuo sino también el mejor. Esta sobrestimación de las cualidades de Pangloss demuestran hasta qué punto el escriptor se burla de él, atribuyéndole cualidades extraordinarias cuando en realidad lo considera inepto. En segundo lugar, en P4, la utilización del adverbio de negación "no, en absoluto" (L4) por parte de Pangloss recalca la seguridad en él mismo. Ahora bien, su habitual logomaquia demostrará su estupidez. Podemos comprobar que la escogencia del nombre hecha por el escriptor no es gratuita: el hecho de que Pangloss (Pan=toda, glossa=lengua) sepa todo sobre todo es irónico, pues él expresa solamente ideas irracionales.

En tercer lugar, el leitmotiv del cuento "el mejor de los mundos" (L5-6), sirve de señal irónica, ya que es un préstamo del vocabulario leibniziano. Maingueneau nos hablaría aquí de una disociación enunciativa: los significantes empleados no corresponden al contexto en que son empleados. Hay aquí un desfase entre el principio de Leibniz y su aplicación a un caso particular como la sífilis. Esta desproporción tiene como objetivo ridiculizar el principio de enlace de causas y de efectos que se torna monstruoso cuando se trata de justificar la existencia de la sífilis debido al descubrimiento del chocolate.

Finalmente, la avalancha de subordinadas causales introducidas por la conjunción "pues" (L7 a 12), y la subordinación relativa (tres casos de "que", L8 a 11) arrebatan toda credibilidad al principio filosófico. La conjunción enmascara bajo una apariencia seria lo absurdo del discurso panglossiano basado en razonamientos teleológicos.

Para su burla, Voltaire maltrata su escritura en beneficio de una subordinación triple, la cual forma una equivalencia sintáctica:

(...) esta dolencia que emponzoña la fuente misma (...)

que con frecuencia llega a impedirla

(...) que es, evidentemente (...) 
Podríamos aproximar este estilo al de Eugène Ionesco en La cantatrice chauve, quien no denuncia como Voltaire una filosofía, pero sí la existencia absurda del ser humano y sus relaciones sociales en la sociedad contemporánea:

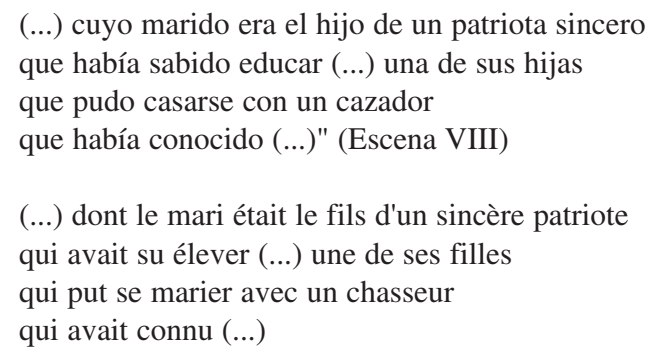

\subsection{Los adjetivos BUEN, SABIO + el sustantivo PANGLOSS}

(E1 P5 y P6 fueron reagrupados, pues contienen los dos "Pan-gloss". Los significantes "cosas admirables" — que forman parte del sentido global del pasaje— serán estudiados en P6).

PASAJE 5 En Cádiz, un franciscano roba los diamantes de Cunegunda

1 Ay! — dijo Cándido- el buen Pangloss me había

2 demostrado a menudo que los bienes terrenales

3 son comunes a todos los hombres, que

4 cada uno tiene igual derecho a ellos. Ese fran-

5 ciscano debía, según estos principios, dejarnos

6 con qué acabar nuestro viaje (56).

1 -Hélas, dit Candide, le bon Pangloss m'avait

2 souvent prouvé que les biens de la terre

3 sont communs à tous les hommes, que

4 chacun y a un droit égal. Ce cordelier devait

5 bien, suivant ces principes, nous laisser de

6 quoi achever notre voyage (43).

PASAJE 6 Llegando a Buenos Aires

1 -Qué lástima, decía Cándido,

2 que el sabio Pangloss haya sido ahorcado, contra

3 todos los usos, en un auto de fe; él nos diría

4 cosas admirables acerca del mal

5 físico y el mal moral(...) y yo

6 me sentiría con fuerzas bastantes para osar

7 hacerle respetuosamente algunas objeciones (86). 
1 - C'est bien dommage, disait Candide,

2 que le sage Pangloss ait été pendu contre la

3 coutume dans un autodafé; il nous dirait

4 des choses admirables sur le mal

5 physique et sur le mal moral(...) et je

6 me sentirais assez de force pour oser

7 lui faire respectueusement quelques ob-

8 jections (53).

Los dos pasajes presentan a Cándido como emisor, el cual utiliza tres adjetivos evaluativos positivos "buen" (P5, L1), "sabio" (P6, L2) — que califican a Pangloss_ y "admirables" (P6, L4). Los adjetivos están ligados a un Sé1 y un Sé2. El Sé2 de los dos primeros adjetivos se adivina gracias al referente Pangloss; el del último adjetivo se deduce por medio del anafórico "él" (P6, L3) que envía al referente.

El Sé1 de "buen" designa a alguien que cumple bien su papel en el trabajo, en sus actividades. El Sé2 puede significar "incapaz". En P6 Cándido llama a Pangloss "sabio", adjetivo cuyo Sé1 indica a una persona que lleva una vida inspirada en un arte superior, que puede ser considerada como modelo, mientras que el Sé2 puede significar "insensato". Finalmente, el Sé1 de admirables designa algo digno de admiración, mientras que el Sé2 significaría desprovisto de todo valor.

En P5, Cándido emplea la interjección "¡ay!" (L1), modalidad apreciativa que marca su pesar en cuanto al hurto cometido por el franciscano. El pluscuamperfecto "me había...demostrado" (L1-2) contiene ironía, ya que Pangloss no prueba nunca nada y sus principios filosóficos poseen solamente fundamentos abstractos.

Este tiempo verbal, intensificado por el adverbio de tiempo "a menudo" (L2), hace resaltar la ironía.

No hay que omitir que en P6 aparece una alusión a Leibniz, por lo que el escriptor emplea "mal físico" y "mal moral", pero por pertenecer la alusión a otro tipo de ironía, nos abstendremos de desarrollar estos conceptos.

Veamos ahora algunos elementos que ponen en relieve la ironía. Primero, la expresión emitida por Cándido "Qué lástima" (L1) manifiesta su pena hacia un ser ignorante: Pangloss. Segundo, algunos significantes pueden ser percibidos como irónicos: el adverbio "respetuosamente" (P6, L7) que nos indica la gentileza de Cándido y el adjetivo "algunas" (P6,L7). Pareciera que el pasaje, teniendo como tema principal Pangloss, los tiñe de valor opuesto: el primero significaría "irrespetuosamente", el segundo "muchas".

Constatamos ahora que en los primeros seis pasajes la ironía desvaloriza a Pangloss y denuncia dos aspectos: por una parte, el lado mecánico de su filosofía se torna evidente en P2 y $\mathrm{P} 4$, con la utilización que se hace del principio de causa y de consecuencia; por otra parte, se destaca la absurdidad del optimismo, pues trata de justificar de una forma anormal la existencia de una enfermedad como la sífilis. 


\subsection{El adjetivo BONITO + el sustantivo ESTADO}

PASAJE 7 En Venecia, Cándido encuentra a Paquette:

1 - Ay, pobre criatura, ¿sois

2 vos entonces quien pusistéis al doctor

3 Pangloss en el bonito estado en que lo he visto? (186)

1 Hélas, ma pauvre enfant, c'est

2 donc vous qui avez mis le docteur

3 Pangloss dans le bel état où je l'ai vu? (100)

El adjetivo evaluativo positivo "bonito" (L3) que hace alarde del sustantivo "estado" expresa la opinión de Cándido y tiene como referente la sífilis. Tratándose de una enfermedad, "bonito" tiene grandes posibilidades de significar lo contrario de su sentido literal. De esta manera, se asocia a un Sé1 (agradable a la vista) y a un Sé2 — deducido al contexto de referencia, sífilis- que podría ser "horroroso".

En P7, Cándido evalúa positivamente el estado sifilítico de Pangloss, estado físico que en realidad el autor menosprecia, lo cual forma parte del mecanismo de la ironía.

La introducción, por medio de una apreciación que utiliza la interjección "¡ay!, deja suponer que el emisor sostendrá palabras que contienen pena o dolor.

A esta interjección se añade el adjetivo afectivo "pobre" que transmite una reacción emocional de lástima de Cándido hacia Paquette. Esta reacción supone de igual manera, que las palabras serán negativas. Ahora bien, el significante "bonito" produce el efecto contrario.

La intención de la ironía en este pasaje consiste en llamar la atención sobre el mal en la tierra, simbolizado aquí por la enfermedad venérea.

\subsection{El adjetivo GRAN + el sustantivo DIGNIDAD}

PASAJE 8 Antes de ir a Constantinopla, Cándido averigua la suma del rescate exigido para la liberación del barón y de Pangloss:

1 -Perro cristiano, respondió el

2 arráez, puesto que estos dos perros

3 galeotes cristianos son barones y

4 metafísicos, lo que sin duda es

5 una gran dignidad en su país, tú me

6 pagarás cincuenta mil sequíes.

7 -Los tendréis, Señor; llevadme (...) (218)

1 - Chien de chrétien, répondit le

2 levanti patron, puisque ces deux chiens de

3 forcats chrétiens sont des barons et des 
4 métaphysiciens, ce qui est sans doute

$5 \quad$ une grande dignité dans leur pays, tu

6 m'en donneras cinquante mille sequins.

$7 \quad$-Vous les aurez, monsieur; ramenez-moi (...) (115)

Como emisor, el arráez — patrón del barco— emplea el sustantivo "dignidad" (L5) que es ambiguo con relación al contexto verbal que le precede "son barones y metafísicos" (L3-4). ¿El hecho de ser barón o metafísico deberá ser considerado como una dignidad? El arráez diría que sí, Voltaire afirmaría que no.

De acuerdo con la realidad brutal en la que se encuentra el arráez (obligar a un número determinado de hombres a remar), podemos presumir que "dignidad" posee un valor contrario. Está unido a un Sé1 (un trabajo que otorga una categoría eminente) y un Sé2 inferido del contexto verbal citado.

Es primordial citar el adverbio "sin duda" (L4), ya que pone en evidencia el valor irónico de "gran dignidad". Asimismo, marca una modalidad lógica que manifiesta la seguridad con la que el arráez habla, actitud ridícula si se examinan sus palabras.

Recordemos que el arráez es musulmán, lo que nos llevaría a creer que, para él, la religión de Cándido, el barón y el metafísico no es digna de consideración. Por esta razón, recurre a términos injuriosos que muestran su desprecio hacia ellos: "perro cristiano" (L1), "perros galeotes cristianos" (L2-3). Este rechazo es intensificado por el siguiente cambio: el paso de un pronombre personal, utilizado aquí peyorativamente ("tú", empleado por el arráez L5) a otro pronombre más respetuoso (el "vos", sobrentendido L7) utilizado por Cándido.

El objetivo de la ironía es en P8, el de desacreditar, por un lado, la nobleza, representada por los barones, y por otro lado, la metafísica, ciencia rechazada por el autor y representada por los metafísicos.

\subsection{El sustantivo HÉROES + el adjetivo ABAROS}

(F.G. Ascot traduce el adjetivo francés "abares" al español "abaros", que representa a los soldados franceses.)

PASAJE 9 Cándido se encuentra en medio de los Búlgaros:

$1 \quad$ Pasó por encima de montones

2 de muertos y moribundos(...) era

3 un poblado abaro que los Búlgaros habían

4 incendiado, de acuerdo a las leyes del derecho público(...)

$5 \quad$ Cándido huyó a toda prisa hasta llegar a

6 otra aldea(...) los héroes abaros la habían

7 tratado de igual manera $(23,30)$.

$1 \quad$ Il passa par-dessus des tas

2 de morts et de mourants(..) c'était

3 un village abare que les Bulgares avaient 


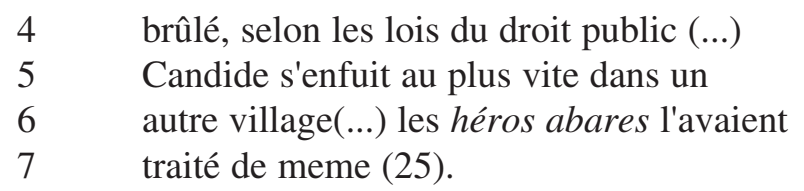

En P9, el emisor no es ya más un personaje sino el narrador. "Héroes" está ligado a un Sé1 donde el sustantivo designaría a un individuo digno de ser apreciado por la sociedad, entregado a una buena causa. Este término es incompatible con el contexto de referencia soldados abaros - que designa en la mente del escriptor, de acuerdo a Goldzink, probablemente a los franceses.

Esta incompatibilidad nos hace creer que el significante se asocia a un Sé2 que puede significar individuos salvajes, vergüenzas públicas.

De acuerdo con Voltaire, los Abaros y los Búlgaros pertenecen a los escitas, pueblos que causaron estragos en Europa Oriental del siglo VI al siglo IX. "Los Franceses (Abaros) y los Prusianos (Búlgaros), por medio de sus guerras, prolongan entonces la barbarie medieval." (Goldzink 1987: 44) No olvidemos que el escriptor aborrece el sustantivo "héroes", de ahí el empleo irónico posible del significante. El narrador habla positivamente de los soldados, mientras que el objetivo probable de Voltaire es desdeñarlos. La ironía produce aquí un efecto de sorpresa, pues "héroes" surge en el momento en el que el lector espera más bien un significante que marque la indignidad.

Existen otros significantes que contienen ironía por referencia: "derecho público" (L4). Si nos reportamos al contexto de referencia, el narrador nos refiere a una idea brutal de la época en donde se consideraba la guerra como un derecho que podía justificar los masacres. Sería entonces útil precisar lo que Montesquieu ya había escrito en 1748 con respecto al derecho público:

Los autores de nuestro derecho público, basados en historias antiguas, (...) cayeron en grandes errores (...) supusieron de los conquistadores, un derecho, (...) el de matar. (...) Está claro que, cuando la conquista está hecha, el conquistador no tiene ya más el derecho de matar; pues ya no está en el caso de defensa natural, y de su propia conservación (1971: 76).

La ironía en P9 -célebre sátira de la guerra- intenta denunciar las brutalidades cometidas por los soldados y los falsos valores concernientes al heroísmo guerrero.

\subsection{El sustantivo SECRETO + el adjetivo INFALIBLE}

PASAJE 10 Después de un terremoto que había destruido gran parte de Lisboa, algunos hombres de saber toman decisiones:

1 ...la Universidad de Coimbra decidió

2 que el espectáculo de algunas

3 personas quemadas a fuego lento, y con gran

4 ceremonial, es un secreto infalible para

5 impedir que la tierra tiemble (48). 
$1 \quad$...il était décidé par l'université

2 de Coimbre que le spectacle de quelques

3 personnes brûlées à petit feu, en grande

4 cérémonie, est un secret infaillible pour

5 empêcher la terre de trembler (34).

El adjetivo "infalible" (L4) utilizado por el narrador se une a un Sé1: algo de lo que se obtiene resultados seguros. Este significante es absurdo si miramos el contexto verbal que le precede y que le sigue; la oración "algunas personas quemadas a fuego lento, y con gran ceremonial" (L2-3-4) es ilógica con relación a la finalidad de la ceremonia "para impedir que la tierra tiemble" (L4-5). De esta observación inferimos un Sé2 que sería "ineficaz".

De hecho, el narrador aparenta presentar como eficaz el quemar seres humanos, acto que de acuerdo al escriptor, es sin ninguna duda, ineficaz; esto forma parte del funcionamiento de la ironía.

Esta actitud en tiempos de la Inquisición contiene rasgos animistas, ya que el hombre le atribuye a la naturaleza un alma y pretende poder influenciarla por medio de sacrificios humanos, actos que podríamos tildar de salvajes y oscurantistas.

Observemos el contraste entre la familiaridad de la expresión "a fuego lento" (L3) y el carácter pomposo de los significantes "gran ceremonial" (L3-4). Riffaterre señala que el lector se confronta a un ejemplo de "polarización" en donde el efecto de estilo nace del contraste entre los elementos (1971: 76).

En este pasaje, la finalidad de la ironía es denunciar las decisiones monstruosas y absurdas de la Inquisición y confirmar la omnipresencia del mal.

Al concluir este análisis, proponemos el siguiente cuadro que resume la antífrasis:

\section{Cuadro 1}

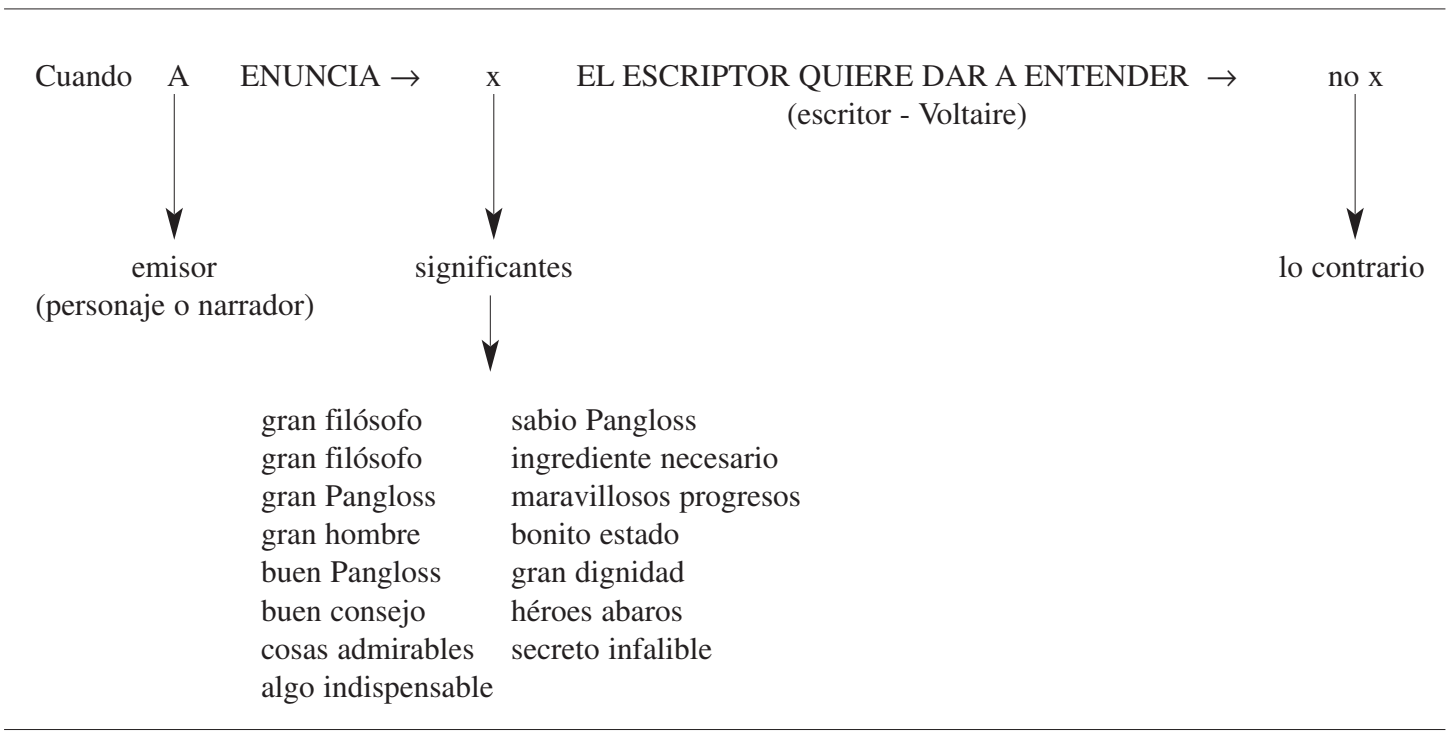


Con base en este cuadro haremos tres observaciones pertinentes:

- Existen cuatro casos del adjetivo evaluativo "gran". Esta frecuencia realza la ironía, pues el escriptor insiste en una cualidad del personaje que es real solamente en apariencia.

- Ocho adjetivos valorizan a Pangloss y sus actos: "gran" (4 casos, indicaremos entre paréntesis para los otros significantes solamente la cifra), "buen" (2), admirables (1), "sabio" (1). Tres adjetivos son utilizados por el personaje: "indispensable", "necesario", "maravillosos". Esto significa que de quince adjetivos, once califican positivamente a Pangloss o son emitidos por él. Esta supremacía entre los significantes pone en evidencia a Pangloss, el objeto principal de la ironía y portavoz de Leibniz.

- Once adjetivos evaluativos y un sustantivo se presentan como falsos elogios irónicos: "gran" (4), "buen" (2), "admirables" (1), "sabio" (1), "maravillosos" (1), "bonito" (1), "gran" (1), "héroes" (1). Los otros tres adjetivos no son valorizantes, pero el emisor los presenta como esenciales ("indispensable", "necesario") o eficaces ("infalible").

\section{Conclusiones}

Este estudio muestra que Cándido es el emisor de cinco de diez pasajes. No es sorprendente que el escriptor haya hecho responsable de la enunciación un personaje ingenuo que es inconsciente de las absurdidades que enuncia. El autor mantiene siempre una distancia entre el enunciado y sus personajes. Es conveniente recordar que el pronombre "yo" aparece una sola vez a lo largo del cuento.

Los ocho primeros pasajes estudiados reflejan la predilección del escriptor por el estilo directo. Es una astucia para llevar a cabo su combate contra la filosofía optimista, sin asumir totalmente la responsabilidad de lo enunciado.

Hemos comprobado que en los diez pasajes, la enunciación contiene pocas modalidades lógicas. Pocos enunciados se sitúan como probables o inciertos; no cabe la menor duda de que esto es debido a que los enunciados de carácter hipotético tienen un valor irónico menos fuerte. En cambio, las modalidades apreciativas son numerosas, y estas acentúan aún más la absurdidad de que son objeto individuos o ideas.

Es importante recalcar también que el emisor nombra siempre lo positivo para sugerir lo negativo, artimaña utilizada de principio a fin.

Es claramente perceptible que la ironía dispone de una serie de elementos que subrayan primordialmente la inanidad de la filosofía de Leibniz, entre ellos: adjetivos, sustantivos, adverbios, oraciones subordinadas, interjecciones; estos son factores esenciales que engendran el significado. Existe también una exageración en la manera de tratar a los personajes, los objetos, las situaciones banales, con el objetivo de acentuar lo ridículo y absurdo de la filosofía optimista.

Es un hecho evidente que el autor obliga al lector a sacar conclusiones.

Finalmente, creemos que Cándido está lejos de caer en desuso, debido a los temas abarcados por Voltaire. Si pensamos en la antigua Yugoslavia o en la Argelia actual, nos vendrían a la mente hechos vergonzosos, dolorosos, de carnicería humana, semejantes a los que se produjeron hace más de doscientos años. 


\section{Bibliografía}

Allemann, B. 1978. "De l'ironie en tant que principe littéraire". Poétique. (36): 385-98.

Benveniste, Emile. 1966. Problèmes de linguistique générale. Paris: Gallimard.

Dictionnaire des littératures de langue française. 1987. Paris: Bordas.

Fontanier, Pierre. 1977. Les figures du discours. Paris: Flammarion.

Goldzink, Jean. 1987. Voltaire. Candide ou l'optimisme. Beaume-les-Dames: Magnard.

Haffter, Pierre. 1967. L'usage satirique des causales dans les contes de Voltaire. Genève: Institut et muséeVoltaire.

Jakobson, R. 1963. Essais de linguistique générale I. Paris: Editions de minuit.

Kerbrat-Orecchioni, Catherine. 1979. De la sémantique lexicale à la sémantique de l'énonciation II. Tesis doctoral: Universidad de Lyon II.

1980. "L'ironie comme trope." Poétique. (41): 118-27.

1980. L'énonciation de la subjectivité dans le langage. Paris: Armand Colin.

Lemaître, Henri. 1985. Dictionnaire Bordas de littérature française et francophone. Paris: Bordas.

Maingueneau, D. 1976. Initiation aux méthodes de l'analyse du discours. Paris: CIé International.

Moirand, Sophie. 1979. Situations d'écrit. Paris: Clé International.

Montesquieu. 1971. De l'esprit des lois I. Paris: Garnier Flammarion.

Muecke, D.C. 1978. "Analyses de l'ironie." Poétique. (36): 478-94.

Peytard, Jean. 1974. Littérature et classe de langue. Paris: Hatier.

Riffaterre, Michael. 1971. Essais de stylistique structurale. Paris: Flammarion.

Trésor de la langue française. 1983. Paris: C.N.R.S.

Voltaire. 1983. Candide ou l'optimisme. Paris: Librairie générale française.

Voltaire. 1942. Cándido. Traducción española de F.G. Ascot. México: Ediciones Quetzal. 